\title{
Waveguide Power Combiner Demonstration for Multiple High Power Milllimeter Wave TWTAs
}

\author{
E.G. Wintucky, R.N. Simons \\ NASA Glenn Research Center, 21000 Brookpark Rd., Cleveland, OH 44135 \\ Email: Edwin.G.Wintucky@nasa.gov, Tel: 216-433-3510
}

\author{
G.G. Lesny
}

Alphaport Inc.

c/o NASA Glenn Research Center, 21000 Brookpark Rd., Cleveland, OH 44135

Email: Gary.G.Lesny@grc.nasa.gov, Tel: 216-433-6261

\author{
J.L. Glass \\ Lockheed Martin \\ c/o NASA Glenn Research Center, 21000 Brookpark Rd., Cleveland, OH 44135 \\ Email: Jeffrey.L.Glass@grc.nasa.gov, Tel: 216-433-3531
}

NASA is presently developing nuclear reactor technologies, under Project Prometheus, which will provide spacecraft with greatly increased levels of sustained onboard power and thereby dramatically enhance the capability for future deep space exploration. The first mission planned for use of this high power technology is the Jupiter Icy Moons Orbiter (JMO). In addition to electric propulsion and science, there will also be unprecedented onboard power available for deep space communications. A $32 \mathrm{GHz}$ transmitter with $1 \mathrm{~kW}$ of RF output power is being considered to enable the required very high data transmission rates. One approach to achieving the $1 \mathrm{~kW} \mathrm{RF}$ power, now being investigated at NASA GRC, is the possible power combining of a number of 100-150 W TWTs now under development.

The work presented here is the results of a proof-of-concept demonstration of the power combining Ka-band waveguide circuit design and test procedure using two Kaband TWTAs (Varian model VZA6902V3 and Logimetrics model A440/KA-1066), both of which were previously employed in data uplink evaluation terminals at $29.36 \mathrm{GHz}$ for the NASA Advanced Communications Technology Satellite (ACTS) program. The characterization of the individual TWTAs and power combining demonstration were done over a $500 \mathrm{MHz}$ bandwidth from 29.1 to $29.6 \mathrm{GHz}$ to simulate the Deep Space Network (DSN) bandwidth of 31.8 to $32.3 \mathrm{GHz}$. Figures 1-3 show some of the power transfer and gain measurements of the TWTAs using a swept signal generator (Agilent $83640 \mathrm{~b}$ ) for the RF input. The input and output powers were corrected for circuit insertion losses due to the waveguide components. The RF saturated powers of both ACTS TWTAs were on the order of $120 \mathrm{~W}$, which is comparable to the expected output powers of the $32 \mathrm{GHz}$ TWTs. Additional results for the individual TWTAs will be presented (AM/AM, AM/PM conversion and gain compression), some of which were obtained from swept frequency and power measurements using a vector network analyzer. The results for the power combining demonstration as well as a more detailed description of the power combining test circuit and test procedure will also be presented. 


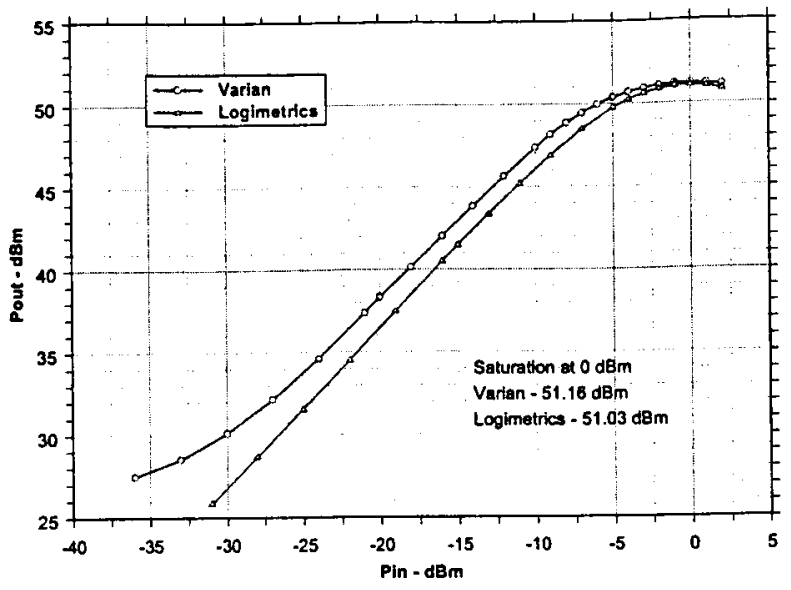

Figurel. Power transfer curves at $29.35 \mathrm{GHz}$

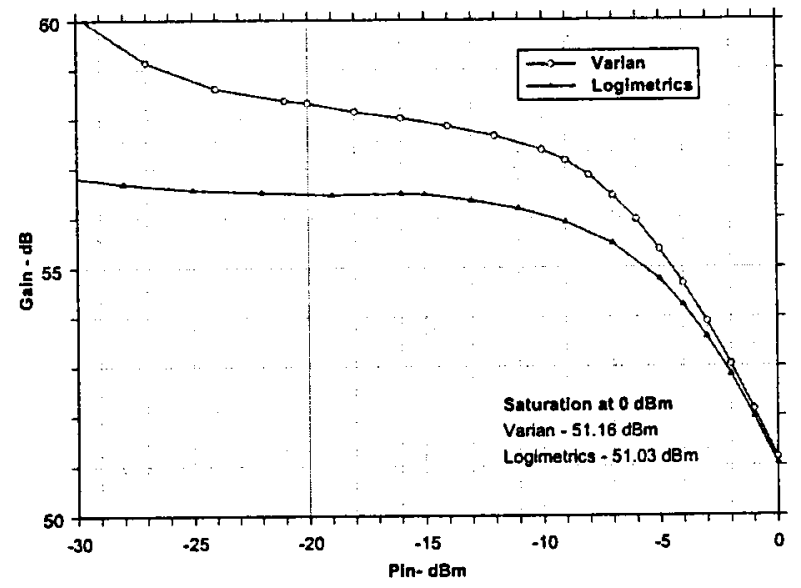

Figure 2. Comparison of gain at $29.35 \mathrm{GHz}$

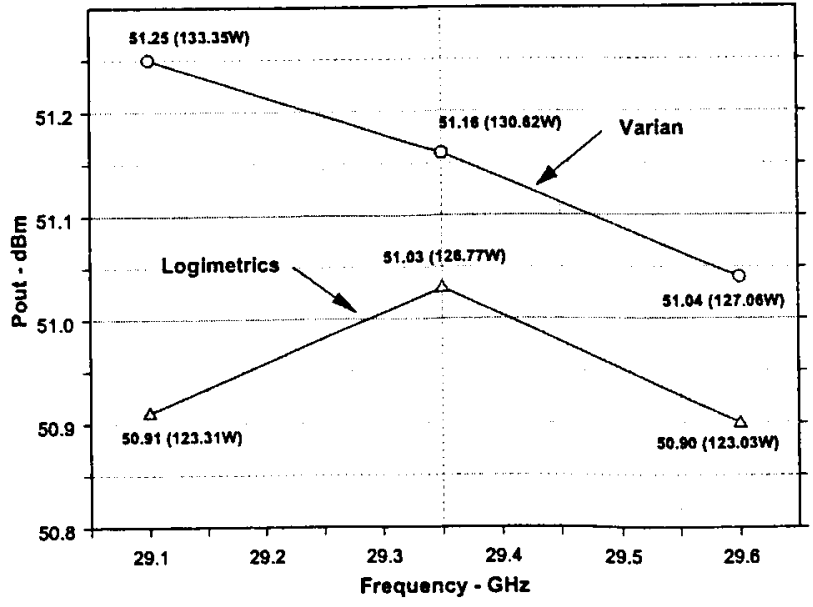

Figure 3. Saturated powers at $29.1,29.35$ and $29.6 \mathrm{GHz}$ 